The eight emulsion-making laboratories are grouped on the ground-floor, and their design has evolved from many years of experience. They are provided with stirring and mixing apparatus for the precipitation of silver halide under closely controlled conditions, and thermostatically controlled tanks for heat treatment. The 'safe-lighting' and ventilation of these laboratories have needed careful planning to achieve the best possible working conditions with the greatest efficiency.

The problems of the emulsion chemist arise in the first place from the variety of films that are nowadays called for. The fast panchromatic films of the miniature camera are closely related to those of the cinema industry, and a little more distantly to the films which meet the needs of zerial photography or oscillograph recording in various forms. The range of emulsions of high contrast used in X-ray work, medical or industrial, are entirely different products. The graphic arts also make their demand on the emulsion makers' time and ingenuity, and the problems met in the development and production of films for colour photography are the most complex of all. Work devoted to the improvement of all these materials is constantly in progress.

The emulsion chemist's task is not by any means limited to production of a material which has the required characteristics of sensitivity, contrast and freedom from fog or from troublesome grain. Besides these and other 'sensitometric' charscteristics there are other qualities that the material must possess to give satisfaction under all conditions of handling or mishandling, and these call for a study of such factors as surface hardness, surface friction, wettability, water absorption and the melting point of the swollen emulsion, and the means to modify these qualities. Problems of colloid chemistry arise here, as they do also in the manufacturing process itself. These problems are ultimately technological ones for the emulsion chemist to solve, but the Ramsden Laboratory has a section where rheology and surface chemistry and physics, as they relate to photographic processes, are to be the subjects of basic investigations.

A small department fully equipped for microscopy and photomicrography will provide essential service to all departments of the Laboratory.

The testing of a trial emulsion presents a special problem and covers not only the characteristics of its sensitivity to light but also other features such as resolving power, graininess and physical properties like its susceptibility to scratching or melting point. Nearly all these tests are peculiar to the photographic laboratory, and it is necessary to develop most of the testing equipment within the organization. This is generally part of the work of the physics labor. atory which, by the application of physical principles, will first devise the test and then produce at least a working prototype of the final routine test oquipment. The physics laboratory is provided with a well-equipped workshop and drawing office which is capable of light precision engineering and can build all kinds of equipment from the odds and ends required in the construction of research 'lash-ups' to a full-scale continuous processing machine for handling cinematograph film. Such a machine is, in fact, being constructed for installation in the processing soction and will be capable of processing 35-mm. and 16-mm. colour film. For experimental work a high degree of versatility is required, and the machine will be able to perform any sequence of operations likely to be called for in research on new processes of colour photography, which is one of the chief preoccupations of the physics laboratory to-day. Present-day colour materials start with a more or less conventional black-and-white emulsion having special features which are the product of research in the emulsion laboratories. The problem of introducing colour is one involving both chemistry and physics, and the particular problem of the colour reproduction obtained is very much the concern of the physicist.

Another section of the physics laboratory is concerned with electronics. The use of equipment coming under this general hoading is growing rapidly, particularly in testing instrumentation and its progress towards more and more automation. Electronics has in this way played its part in developing colour photography and now it seems to be entering the field of commercial printing of colour materials.

The photographic industry depends more than most industries on its research laboratories, and this new laboratory at Brentwood, which was visited by the Duke of Edinburgh on December 6, is the third new laboratory designed and built by Ilford Limited since the Second World War.

\section{RESIDUES OF PESTICIDES IN FOODSTUFFS}

$A$ JOLNT meeting of the Pesticides Group of the Society of Chemical Industry with the Associa. tion of British Insecticide Manufacturers was held on October 21 to discuss "Residues of Pesticides in Foodstuffs". The chairman of the Pesticides Group, Dr. F. P. Coyne, said that the intention of his committee in organizing the discussion was to give those in the chemical industry engaged in trying to apply current regulations an opportunity to air their views on this rather controversial matter. The Association of British Insecticide Manufacturers had welcomed the proposal and had nominated three speakers who would be recognized as authorities on the particular aspects which they discussed, but none of whom would wish to be taken as speaking for every member of the Association. The presence of 160 in the audience was some indication of the interest aroused, and there would have been at least forty more had seating capacity been available.

The following papers were delivered: "Existing Regulations in the U.K. and Overseas" by Mr. J. I. Hendrie ; "Pesticide Residues and Public Heelth" by Dr. E. F. Edson; and "Determination of Residues" by Mr. J. M. Winchester.

Since the United States and Britain appeared to have progressed more than other countries in pro. viding public asfeguards, it was inevitable that the two very different procedures should be compared and contrasted. In the United States no new pesticide can be marketed before the Food and Drug Administration has laid down a tolerance, and if this limit be exceeded the whole of the treated crop is subject to confiscation. In Britain, a voluntary system of notification of new pesticides operates, and there is no provision for enforcement. The principle adopted is to agree on treatments that will result in no toxic hazards to the consumer, and this is considered preferable to any definition of permitted residues. It was stressed that tolerances in the United Stater do not in themselves indicate basic toxicity to humans, since the Food and Drug 
Administration is charged by Congress to prevent unnecessary contamination of food, and its tolerance always takes into consideration the minimum biologically effective dosage-which may differ for different posts on different crops and which relate only to conditions in the United States.

It would be surprising if two such systems had evolved along exactly the same lines, and the factor of legal enforcement probably tends to make the Food and Drug Administration more meticulously precise in its demands. None of the sperkers suggested that its requirements were in any way fallacious, but doubts were expressed as to whether all the routine requirements were essential. A recent report from the United States, that the combination of two organo-phosphorus pesticides at residue levels within the permitted tolerance for each caused effects on experimental animals greater than could have been anticipated as normally additive, raised the question of 'potentiation'. 'This could mean that any new pesticide must be tested in combination with all others to prove its absence of hazard and, while no objection could be made were the case for such action fully proved, the greatest care was needed in ensuring that any such requirement was justified to the full, because of the implications. Theoretically, the possibility of such a happening could not logically be restricted to chemically similar compounds.

Some fear was expressed that the superficial attractiveness of stated tolerances would tend to make other countries favour the United States system, and that without the excellent facilities and high standards of operation in the Food and Drugs Administration there could arise a series of uncoordinated demands on industry, many of them quite unjustified. The analytical side is completely dependent upon the methods available, about which there is frequent disagreement even at national levels. This is one of the reasons why British officials are not enthusiastic about stated tolerances.

Toxicological work presents even more complications, not only in the choice of techniques but also in the interpretation of findings, and Dr. E. F. Edson advocated caution at this early stage, although he was satisfied that there are no grounds for active apprehension. He suggested, and was supported by Mr. J. M. Winchester, that consideration should be given to more extended feeding tests as alternatives to exhaustive chemical investigations into possible metabolites of pesticides. Both speakers agreed with Mr. J. I. Hendrie that eloser collaboration between Government and industry is necessary in order to define more accurately the essential requirements. A Board of Trade investigation into demands of overseas countries is being carried out and should elaborate the position reviewed by the first speaker. Efforts to draw up an agreed scheme of testing are at present boing made by official and industrial toxicologists in Britain, and such a contribution could well form the basis for discussions with other countries.

Emphasis was laid on the sense of responsibility of the industry and on its desire to do all that is necessary to protect the public ; but it was pointed out that if the difficulties of development of a pesticide became so onerous that the prospects of adequate commercial return appeared to be too remote, finance in the chemical industry will undoubtedly be directed into other channels-as a simple duty to shareholders. Even to-day it is widely agreed, both in the United States and Great Britain, that it is not worth while to attempt to develop a new speciality product with very limited markets, no matter how important the problem involved may be to the branch of agriculture or horticulture concerned. This applies whether the potential pesticide bo highly toxic or relatively harmless to humans, since the same procedure must be followed and the same order of expenditure incurred.

In attempting to summarize the three papers, the chairman pointed out that all three contributors were making a case for co-ordination of international standards, in principle at least. It seemed possible, however, that if Britain desired some general international agreement, she may have to be the first to modify current practice. Already in Britain there are tolerances for a limited number of preservatives of foodstuffs, which include fungicides. It would not require any fundamental change to extend these to insecticides, wөedkillers, etc. If some such action could be taken there would probably be a much better chance that the system operating in Britain would be acceptable elsewhere.

Opening the discussion, Sir Solly Zuckerman paid a tribute to British industry, not only for its highly developed sense of responsibility, but also for its most co-operative attitude on the voluntary notification scheme. He refused to be perturbed by the present situation, and considered that the essential costs must be shared by government, industry and the user of pesticides. Since Britain, as well as being a leading importer of foodstuffs is also a considerable exporter of chemicals, it was doubly important that we should take a lead in this matter. He advocated caution, however, in making an approach to United Nations agencies, such as the World Health or Food and Agriculture Organizations, which could ultimately be important and helpful, until more progress had been made in settling Britain's own admitted difficultios in chemical and toxicological testing and interpretation. If the collaboration alresdy existing between industry and government were continued in the same spirit he was hopeful that the chief difficul. ties could be overcome.

An animated discussion followed with views and comments from chemists, toxicologists and administrators in government and in industry. It was clear that everybody concerned was well aware of the difficulties, but there was less unanimity on how to overcome these. A tendency to generalize rather too freely from particular examples was perhaps excusable with such a complex issue, particularly in view of the short period during which current regulations have been operating, either in the United States or Britain. The papers and discussions will be published in full elsewhere.

F. P. CoYne

\section{PHYSICS IN INDIAN UNIVERSITIES}

$\mathrm{U}$ NDER the auspices of the Indian University Grants Commission, the University of Calcutta arranged a seminar on physics which was held during September 9-11. The conference was attended by Dr. W. W. Buechner, professor of experimental physics in the Massachusetts Institute of Technology, and by delegates from almost all the universities in India at which physics is taught at a postgraduate level, together with representatives from a number of other research institutes. The second and third days of the seminar were devoted to papers on nuclear physics and cosmic rays. 